\title{
Trabalho e utopia na modernidade
}

\author{
Suzana Guerra Albornoz ${ }^{1}$
}

\begin{abstract}
O texto explora a obra Utopia (1516), de Thomas More, em especial o que ali é dito sobre o trabalho, sua organização e distribuição na sociedade. Começa lembrando a polêmica em torno do livro, incluído na tradição da escritura em via oblíqua, segundo Leo Strauss e Miguel Abensour, e procede à revisão do que More diz do trabalho a propósito da ilha imaginária ideal.
\end{abstract}

Palavras-chave: Utopia, More, via oblíqua, trabalho, agricultura, artesanato, moderação, igualdade.

$\mathrm{N}$ a Modernidade, a categoria do trabalho se tornaria central. Esta época da história das civilizações, especialmente, do Ocidente, é também uma das mais ricas na produção de utopias, a ponto de se poder dizer que a história da utopia está intimamente relacionada com o surgimento do que se chamou de era moderna. Isso muito embora o sonho humano de um mundo sem sofrimento e perfeitamente organizado possa ser considerado como um dado antropológico, presente em todas as épocas e culturas, e é o que se apresenta veementemente, por exemplo, na República de Platão, na Antigüidade grega, ou na Cidade de Deus, de Santo Agostinho, na antiga Roma recém convertida ao cristianismo.

Nesta fase de nossa pesquisa será realizada uma peregrinação pelos textos modernos que demonstram o trabalho de imaginação da cidade perfeita, desde o período decisivo da Renascença, empreendendo a travessia desse fluxo utópico literário moderno, contemporâneo das descobertas das novas dimensões do mundo planetário e do universo, seja que se tenha chamado propriamente Utopia, como o famoso livro de Thomas More - ou Morus -, ou Cidade do Sol, como na obra de Tomasio Campanella (1980); seja que adquira as denominações mais variadas e fantásticas, como na diversa e abundante produção de textos utópicos dos séculos XVIII e XIX, sobretudo na França, mas também na Inglaterra e alhures.

A obra de Ernst Bloch, ou seja, a nova interpretação da história da utopia, revista e fundamentada de modo antropológico e ontológico, que se encontra sobretudo em sua obraprima O Princípio Esperança, tem-nos servido de inspiração e de guia. É nosso intuito, contudo, abrir uma nova senda, direta, ao mundo das utopias, passagem a que os grandes caminhos do Princípio Esperança convidam e desafiam.

Assim, procederemos aqui a uma releitura comentada, um diálogo com alguns desses textos antológicos que apresentam o caráter de projeto de um mundo melhor, que marcaram os séculos dos Tempos Modernos que precederam a nossa "era dos extremos" - tal como o historiador Eric Hobsbawn denominou o nosso século XX das duas grandes guerras mundiais, dos totalitarismos e da Guerra Fria.

Dentro desses textos antológicos, selecionados por critérios de significação, perseguiremos sobretudo aquelas páginas que se dedicaram à questão do trabalho e de sua organização.

\footnotetext{
${ }^{1}$ Professora do Departamento de Ciências Humanas da UNISC de Santa Cruz do Sul, Rio Grande do Sul. Entre outros livros, publicou: Ética e utopia. Ensaio sobre Emst Bloch (Movimento, 1985); O que é trabalho? (Brasiliense, 1986/2002); O enigma da esperança. Ernst Bloch e as margens da história do espírito (Vozes, 1999); O Exemplo de Antígona. Ética, educação e utopia (Movimento, 1999); Violência ou não-violência. Um estudo em torno de Ernst Bloch (Edunisc, 2000/2002).
} 


\section{O trabalho na Utopia (1516) de Thomas More}

É bem conhecida a polêmica sobre a autoria da obra Utopia, publicada sob a responsabilidade de autor de Thomas More. Parece estabelecido que há fundamento em pensar que Erasmo de Rotterdam terá feito sua leitura antes da publicação e que teria tido a liberdade mesmo de fazer algumas modificações no texto de seu amigo More, como confirma Ernst Bloch, em O Princípio Esperança, para quem o livro, na verdade, "mais que provavelmente" seria uma obra híbrida dos dois grandes autores e humanistas da Renascença.

Além dessa polêmica sobre a influência de Erasmo sobre a pequena grande obra, discute-se também se a intenção de confrontar o ideal à realidade se prenderia afinal à crítica do Estado tal como existente na ilha da Inglaterra ou se, com objetivo mais puramente religioso, More estaria, na direção da tendência reformadora de sua época, confrontando menos a Inglaterra à ilha ideal, antes, Roma ao Monte Athos, onde os monges viviam em sua comunidade a pureza do comunismo cristão primitivo.

Essa parece ter sido a interpretação dada pelo filólogo Heinrich Brockhaus, mas o filósofo da utopia concreta não a endossa. Bloch reconhece no livro e nas idéias da Utopia de More a expressão de um pensamento crítico às realidades européias e inglesas daquele momento de afirmação da burguesia, com suas contradições.

O burguês se agitava, buscava o que lhe era próprio e lhe permitiria desenvolver-se. Suas palavras de ordem eram o trabalho, a via livre aos que merecem, o fim das distinções de classe (Bloch, 1982, p. 88).

Era diante dessa nova posição ante o trabalho e a igualdade social que a pequena obra literária do cristão Thomas More se manifestava.

Antes de entrarmos diretamente no texto de More, julgo interessante deixar aqui registrada a existência de uma outra polêmica, ainda não bem resolvida, sobre o modo como esse livro deveria ser lido.

Em L'utopie de Thomas More à Walter Benjamin, o professor francês Miguel Abensour propõe o que lhe parece ser mais adequado e de acordo com o caráter do texto e do autor, em conjunção com as circunstâncias que em seu tempo cercavam autor e texto. Trata-se da proposta de uma leitura por ele designada como em via oblíqua.

Sem se ter esse cuidado, ou seja, levando-se a Utopia inteiramente ao pé da letra, como se fosse uma proposta de organização estatal direta, sem se considerar a via oblíqua, que significa através de um texto literário e ficcional desenvolver a intenção de fazer pensar e criticar as realidades da Inglaterra daquele tempo - muitas vezes, pelo contraste, ou mesmo, pelo paradoxo, em todo caso, com a distância da ironia - pode-se cair na tentação de remeter a Utopia, injustamente, à genealogia do totalitarismo.

A polêmica em torno do modo próprio da leitura do livro e romance Utopia, como em muitos outros casos, dividiu-se entre leituras realistas e leituras alegóricas.

Por outro lado, também como em outras polêmicas, sobre outros objetos e eventos da história política e da história das idéias, nos últimos séculos os intérpretes estiveram muitas vezes divididos entre católicos, de um lado, e socialistas e comunistas, de outro. Enquanto os socialistas reivindicavam o autor da Utopia como precursor do socialismo, a Igreja Católica, julgando isto um engano, beatificou Sir Thomas More em 1886 e o canonizou em 1935. 
Karl Kautsky (1920) apresentava Thomas More como um excepcional precursor do socialismo moderno. More seria o verdadeiro pai do "socialismo utópico", em geral denominação atribuida aos utopistas franceses ou ingleses da primeira parte do século XIX.

Para os críticos católicos, como, por exemplo, R. W. Chambers (1935), a leitura socialista da Utopia é um abuso e um contra-senso histórico. A inspiração de More estaria antes no passado que no futuro. Sua intenção, ao apresentar uma cidade pagã virtuosa, seria despertar a vergonha dos leitores cristãos que não haviam conseguido instaurar sequer " $a$ perfeição muito relativa de uma cidade fundada apenas na razão humana" (Abensour, 2000, p. 38).

More seria assim interpretado como um autor, digamos, "reacionário", que defenderia a restauração dos valores do mundo medieval, contra o maquiavelismo, ou seja, o realismo político a exemplo de Maquiavel, em processo de afirmação na Renascença.

Abensour aponta que, mesmo não havendo uma ligação necessária entre as interpretações católicas e as leituras realistas, os intérpretes católicos, assim como os marxistas, muitas vezes incorreram no mesmo erro de haverem abandonado a preocupação com o próprio da retórica de que More participa, de não perceberem o caráter alegórico do texto, ignorando as questões relativas à arte da escrita, tão cara justamente naquele tempo, para More como para Erasmo de Rotterdam ou para o próprio Maquiavel.

O referido autor entende por "leituras alegóricas" aquelas como exigia o crítico católico André Prévost, que destacam a questão da escrita, que dão prioridade ao aspecto literário da Utopia de More e, enquanto assim procedem, nesse movimento fazem desaparecer, como que apagam o caráter político da obra, o pensamento da elaboração do projeto do melhor regime de governo e de organização da cidade. A Utopia, assim, acaba deixando o plano da questão política para transformar-se em experiência espiritual, que deve desembocar, como é próprio da alegoria, numa lição moral.

Segundo essa interpretação, o romance político Utopia participa de um gênero que se pode dizer como de escrita indireta, onde as diversas máscaras dos personagens inventados, mesclando-se de modo ousado aos realmente existentes, propiciam a reflexão crítica sobre o poder instalado no presente histórico. $\mathrm{O}$ aspecto literário e o político, como também o moral, não podem ser esquecidos nem separados sem que se perca o sentido da obra e a intenção de More.

A Utopia teria um sentido político não independente do modo como More escreve e do que ali se diz, mas justamente no seu dizer e na forma desse dizer. O texto de Thomas More participaria de um gênero de escrita sofisticado e extemporâneo, uma arte de escrever esquecida, conforme nos podem orientar as teses de Leo Strauss (1979).

A propósito da definição dessa escrita indireta ou via oblíqua do pensamento político que atravessa a produção literária, Leo Strauss se refere ao julgamento de Sócrates, acontecimento paradigmático e de certo modo fundador, em nossa história ocidental, da relação entre os filósofos e o poder, a cidade, o Estado. Quando Sócrates fez uma intervenção nova, de estilo novo, na cidade, demonstrou imprudência. $O$ caso de Sócrates chama a atenção sobre o fenômeno da perseguição que ameaça a pesquisa filosófica em toda cidade humana. Segundo Strauss, a pergunta prática que se coloca aos filósofos, pois, é de como se deve comunicar um pensamento independente, suscetível de revolucionar a ortodoxia de uma dada sociedade, sem se expor ao mesmo fim trágico de Sócrates.

O movimento próprio da filosofia é operar uma passagem da opinião, que circula e predomina na cidade, que visa a reproduzi-la tal como é, para o conhecimento de "todas as coisas", conhecimento suscetível de subverter a ordem política, submetendo-a a questões que não são mais as da opinião. 
Ou seja, o trabalho da filosofia é o de substituir a opinião pelo conhecimento. Strauss reconhece, assim, que a filosofia atinge um elemento essencial na sociedade, que a compõe e constitui internamente, a saber, a opinião. "A filosofia ou ciência é, pois, a tentativa de dissolver o elemento no qual a sociedade respira, e assim, ela põe em perigo a sociedade" (Strauss, 1979, p. 244; Abensour, 2000, p. 44).

Se o filósofo pode escolher respeitar as opiniões de uma dada sociedade, no entanto, não é obrigado a considerá-las como verdadeiras. É próprio de um pensamento livre estar referido a si mesmo, encontrar em si mesmo o seu limite, quer dizer, não tolerar nenhum limite externo. Como satisfazer a essa exigência, de um pensamento independente, sem provocar perseguição, sem se expor à reação agressiva da sociedade cuja opinião é contrariada?

A partir de obras do período medieval judeu-árabe da produção filosófica, Leo Strauss redescobre uma técnica de escritura particular, que consiste em escrever "nas entrelinhas". Arte secreta de escrever de tal modo que um pensamento livre possa dedicar-se à pesquisa da verdade sem ferir abertamente a opinião, logo, evitar ser ferido, protegendo-se da perseguição.

São múltiplos os procedimentos característicos desse tipo de escritura: a obscuridade do plano, falsas citações, pseudônimos, expressões estranhas, repetições inexatas de afirmações anteriores. A contradição intencional é o procedimento mais marcante. Funciona como um sinal de alerta para o leitor atento, que é desafiado a descobrir a intenção secreta do autor. O escritor que recorre a essa técnica de escritura - para Strauss, segundo Abensour - visa atingir leitores capazes de pensar e dignos de confiança, apostando que o desejo de verdade se acompanha do anseio de liberdade.

Infelizmente, essa é uma experiência que temos bem presente na memória - nós, escritores brasileiros - de quando tentávamos escrever ensaios críticos da sociedade nos anos de chumbo da ditadura militar, de 1964-1984, quando o exercício efetivo da censura acompanhava de modo rígido a estreita limitação ideológica da opinião dominante.

Essa arte de escrever seria dirigida a diversos tipos de leitores, reunindo a vantagem da publicação, isto é, da apresentação pública, ao mesmo tempo evitando o risco da perseguição e superando o limite da comunicação privada. Nesse tipo de escritura, tende a instituir-se uma pluralidade de espaços de comunicação: um espaço público, onde o objeto em questão pode ser tratado segundo as exigências da/do cidade/Estado, e um espaço filosófico, onde o objeto é considerado do ponto de vista da verdade. Não se trataria apenas de evitar perseguição das autoridades religiosas e políticas, por causa de afirmações heterodoxas, mas também de prevenir "apropriações doutrinais abusivas":

As idéias do autor de um drama ou de um diálogo não devem, sem prova prévia, ser identificadas às idéias expressas por um ou vários de seus personagens, ou às idéias sobre as quais concordam todos os seus personagens, ou seus personagens simpáticos (Strauss, 1979, p. 239).

Leo Strauss reconhece em Thomas More um dos inventores dessa arte secreta de escrever, designada sob o nome de ductus obliquus. Parece-me prudente termos isto na lembrança ao nos aproximarmos diretamente do texto de Thomas More.

São muitas, pois, as possibilidades e maneiras de compreender e interpretar o texto dessa obra. Poderíamos tomar o Livro I como uma iniciação ao Livro II e o todo da obra talvez deva ser visto como uma alegoria que transporta, com muito jogo de máscaras, uma visão da realidade que permanece velada, por trás das máscaras. Com certeza essa seria uma 
maneira de receber o texto mais rica de insinuações, aberturas e sugestões do que uma apresentação que nele buscasse apenas teses claras.

Contudo, embora conservemos a consciência desse "olhar oblíquo" possível, mesmo, talvez, necessário, a sensibilidade para essa percepção nas entrelinhas, esta não nos deve intimidar e impedir uma análise mais direta do texto. A coragem do enfrentamento direto, quando se sabe que ele não é tudo nem o todo, é o que tentaremos praticar nas próximas páginas.

Em seu romance de caráter político ou moral - que, em latim, era intitulado De optimo rei publicae statu sive de nova insula Utopia ou, como também se encontra em outras edições ${ }^{2}$, De optimo republicae statu deque nova insula utopia, e hoje é mais conhecido pelo título sintético, simplesmente, como Utopia, palavra que pertence aos muitos neologismos produzidos nessa obra literária - Sir Thomas Morus reservava um trecho importante à questão do trabalho, que prometemos aqui priorizar.

No contexto daquela narrativa, que se refere a uma ilha desconhecida dos europeus sobre a qual o autor escreve a Pedro Giles - amigo, como More, do famoso humanista Erasmo de Rotterdam - lembrando as informações que ambos teriam recebido de um suposto viajante ilustre denominado Rafael Hitlodeu, desenha-se um projeto de reorganização política, que contém também uma proposta de redistribuição do trabalho, com caráter de crítica à divisão do trabalho desigual existente entre as classes sociais na Inglaterra da época. Trata-se de uma proposta de nova divisão do trabalho no tempo, durante a jornada comum do cidadão comum, e de sua melhor divisão pelos diversos habitantes da ilha.

Após haver exposto sobre os magistrados da ilha referida por Hitlodeu, o autor dedica um capítulo de seu livro ao aspecto das artes, oficinas e ocupações, tais como teriam sido encontradas na ilha de Utopia, que tanto causava a admiração de quem a havia conhecido ou dela ouvira falar, sobretudo quando se estabeleciam comparações com as outras formas de sociedade até então conhecidas pelos europeus.

A agricultura é a arte comum a todos os utopianos, homens e mulheres, e a atividade em que todos são igualmente peritos e hábeis. São nela instruídos desde a juventude: aprendendo-a nas escolas, em teoria, e praticando-a nos campos vizinhos da cidade, aonde os levam em passeio e recreação, não só para observarem o trabalho agrícola, como para nela exercitarem as forças físicas (More, 1516/1973, p. 69).

Por essa primeira citação do trecho que trata da organização do trabalho, entendido este como trabalho vivo, ou seja, como atividade humana antes que rendimento e produção, já está bem explícita a orientação pró-agricultura e o espírito de conservação do mundo rural, busca ou retorno que se manteria característica das utopias por muito tempo e, quem sabe, seja justamente o traço que separa a utopia da realidade dos tempos modernos, onde se desenvolveriam de tal modo o mundo urbano e o aparato da técnica, da indústria e da tecnologia.

Na ilha de Utopia, contudo, não apenas a agricultura há de concentrar a atividade humana:

Além da agricultura, que, como referi, é conhecida e praticada por todos, cada um deles aprende outro ofício, como profissão própria. Normalmente, ou se dedicam à tecelagem de lã e do linho, ou aprendem o ofício de pedreiro, ferreiro ou carpinteiro. Nenhuma outra profissão, além destas, é tão usual que mereça aqui menção especial (More, 1516/1973, p. 70).

\footnotetext{
${ }^{2}$ Por exemplo: a edição da Editora da UnB, Brasília, 1980.
} 
Cabe ressaltar como, aqui, a profissão se identifica com o ofício, quer dizer, com a atividade própria do artesanato, enquanto a agricultura, se é praticada por todos, ainda assim e talvez por isso mesmo, não é considerada como uma profissão; trata-se da atividade natural geral que a todos obriga e a ninguém identifica.

Por outro lado, a austeridade é o meio de não deixar haver nem desperdício de trabalho humano, nem exigência de trabalho desnecessário. Isso vai aparecer também nas regras imaginadas para o consumo, nos limites postos aos desejos de ostentação ou de luxo:

O vestuário tem a mesma e invariável forma para toda a ilha, salvo a distinção entre o vestuário feminino e o masculino e a diferenciação pelo traje de solteiros e casados. $\mathrm{O}$ vestuário é cômodo, agradável, elegante, facilitando os movimentos do corpo, adequado para todas as estações (More, 1516/1973, p. 70).

As regras para o uso do vestuário são imaginadas de modo a dar forma e limite ao trabalho, pensado sempre de modo igualitário, ou seja, distribuido por todos os habitantes.

Cada família confecciona o seu próprio vestuário. Quer os homens, quer as mulheres aprendem forçosamente um dos ofícios acima mencionados. As mulheres, por serem de natureza mais frágeis, são encarregadas das tarefas mais leves. Como a tecelagem da lã e do linho, estando reservados aos homens os trabalhos mais pesados (More, 1516/1973, p. 70).

Não fica muito claro se essas regras são estabelecidas com vistas à sustentação da vida social, que condicionaria o modo de produzir e de trabalhar, ou se o autor faz questão de que todos participem do trabalho porque lhe confere um caráter humanizante, formativo. Fato é que aparece no texto a preocupação com o trabalho adequado, considerada a atração pessoal por determinada atividade, logo, afirmado o conteúdo positivo intrínseco, subjetivo, da atividade produtiva.

Na maior parte dos casos, os indivíduos são iniciados na profissão paterna, pois habitualmente a ela são predispostos pela natureza. No entanto, se alguém se sentir atraído por outro ofício, entra adoptivamente numa família que exerça a profissão que o atrai. Tanto o pai como os magistrados providenciarão para que dê entrada numa família respeitável e honesta (More, 1516/1973, p. 70).

As diferenças individuais são referidas como dignas de respeito, o que é moderno, novo naquele período da passagem do mundo medieval ao renascentista. Contudo, ainda parece aceitável o costume dos séculos passados de providenciar a iniciação ao ofício em outra família, que não a de origem.

Se um indivíduo, embora tendo já uma profissão, queira aprender outra, lhe é lícito fazêlo. Na posse de ambas as profissões, pode escolher a que preferir, a menos que a cidade tenha mais necessidade de uma que da outra (More, 1516/1973, p. 70).

Variações individuais e multiplicidade de saberes profissionais caminham juntas. A possibilidade de escolha entre uma ou outra profissão, a existência de uma alternativa, encontram sua medida na cidade, pois pode-se escolher "a menos que a cidade tenha mais necessidade de uma que da outra". A cidade vigia para que todos sejam ativos, para que ninguém afunde na ociosidade.

Nesse ponto, Thomas More participa, junto com o movimento de idéias no bojo da Reforma Protestante, sobretudo com Lutero, da revalorização do trabalho, a que a Modernidade procederia e aprofundaria nos séculos a seguir. Mas no seu texto aparece que a exigência do trabalho de todos tem o sentido de evitar que a ociosidade de alguns acabe tornando necessária a escravidão e o excesso de trabalho e cansaço dos outros. 
A função principal e quase única dos sifograntes é velar para que ninguém se entregue à ociosidade, e para que toda a gente exerça a sua profissão diligentemente, não querendo isto dizer que tenha de trabalhar sem descanso, do nascer ao pôr do Sol, como bestas de carga. Isso seria pior que a miserável e desgraçada condição de escravo, embora seja essa a vida dos trabalhadores e artífices, por toda a parte, fora da Utopia (More, 1516/1973, p. 70).

Sifograntes é a denominação dada por More aos magistrados que lideram (30) famílias, estas que fazem parte do grupo maior de comunidade de famílias que constitui a cidade. Na sua visão caberia, portanto, aos magistrados intermediários, líderes de um grupo, de algumas famílias, velar para que o trabalho seja bem distribuído entre todos. Com isso, no entanto, tem-se que a maior parte do tempo do dia não necessita destinar-se ao trabalho.

Coerente com a sua formação, com sua raiz doutrinária imersa no mundo cultural medieval cristão e católico, nosso autor, embora revalorize o trabalho, não lhe concede o centro da vida humana na cidade ideal; não lhe confere a importância maior nem lhe atribui o lugar principal na organização do tempo na ilha de Utopia.

Nesta ilha divide-se o dia e a noite em vinte e quatro horas exatas e destinam-se ao trabalho apenas seis horas: três antes do meio-dia, com intervalo para o jantar, duas de descanso, seguindo-se de mais três horas de trabalho e a ceia. Às oito da noite vão para a cama, dando oito horas ao sono (More, 1516/1973, p. 71).

A More pareceu importante incluir uma recomendação de equilíbrio entre o trabalho, o descanso e o lazer, mesmo que não seja para evitar dar margem a dúvidas, pois, se mantivermos viva a memória da introdução deste texto, com as observações de Leo Strauss apontadas por Abensour, saberemos que a via oblíqua como gênero ou estilo literário nos impede de sustentar uma certeza ingênua e de compreender as frases do texto numa clave simples.

O tempo livre entre o trabalho, as refeições e o sono é ocupado livremente por cada indivíduo, como melhor o entender. Não com o fim de que se possam entregar à preguiça e ao esbanjamento, mas para que, libertos das suas ocupações, se ocupem e empreguem a sua atividade variadamente na arte ou na ciência que mais lhes agrade (More, 1516/1973, p. 71).

Enquanto descreve a ilha de Utopia, More quer salvar-se pela ambigüidade, pela escrita indireta, assim não assume que esteja expressando opiniões suas, pois já vimos que a Utopia se apresenta como relato de um viajante, como descrição objetiva feita por Rafael Hitlodeu. Contudo, parece evidente que, ao relatar num tom de quase admiração explícita, o autor nos dá a impressão de recomendar a seus contemporâneos ingleses outras maneiras de organizar seu tempo, sua vida, seu trabalho e seu lazer.

A indicação da abertura dos utopianos para os estudos é significativa. Sendo obrigação para poucos, o estudo é escolha livre de grande número:

É um costume muito apreciado haver diariamente cursos públicos, de madrugada, a que apenas são obrigados a assistir os indivíduos escolhidos e destinados ao estudo. No entanto, grande número de pessoas, mulheres e homens, freqüentam estes cursos, escolhendo a matéria para que sentem mais inclinação (More, 1516/1973, p. 71).

Parece evidente que, nessa descrição, aparentemente uma constatação relatada pelo personagem, comunica-se uma valoração humanista, a afirmação do valor da educação, a proposta da instrução e do estudo como bens entregues à liberdade humana, disponíveis e 
desejáveis para todos independentemente de diferenças de gênero ou de profissão. A liberdade que cerca a atividade do estudo fica acentuada pela afirmação seguinte:

Porém, se alguém preferir empregar o seu tempo livre na sua própria profissão, como acontece com muitos cujo espírito se não deleita nas ciências especulativas, não o censuram por isso, nem o impedem, antes o louvam, pois assim se torna igualmente útil à comunidade (More, 1516/1973, pp. 71-72).

A afirmação humanista do valor da instrução e do estudo não chega a superar inteiramente a tradição de o trabalho útil ser pensado como independente da instrução.

De todos modos, a liberdade de escolha é algo muito digno de ser registrado, pois não devemos esquecer que a obra foi escrita na Renascença inglesa, no período de passagem aos Tempos Modernos e de recente abertura para mudar as referências milenares da cultura européia da Idade Média, quando muita informação podia parecer perigosa e ameaçadora para a conservação da fé e da fidelidade religiosas.

Depois do jantar ocupam uma hora em divertimentos: no Verão, no jardim, no Inverno, nas grandes salas onde tomam as refeições em comum. Praticam a música ou distraem-se conversando (More, 1516/1973, p. 72).

Revela-se aí mais um traço do humanismo renascentista, ressurgindo das cinzas da herança antiga o prestígio das musas, afirmando-se para o tempo livre, além do trabalho, o direito ao lazer e à distração de cunho artístico, deixando-se um pouco ao lado a alternância entre trabalho e oração - esta que sempre foi, é verdade, na arte sacra e na liturgia, marcada pela expressão artística -, que haviam sido por tanto tempo os eixos do universo monástico medieval e continuariam a pautar as orientações cristãs mais puritanas da Reforma.

Não conhecem o jogo dos dados ou qualquer dos outros jogos de azar, tão perniciosos e loucos. Jogam, porém, dois jogos que se assemelham ao nosso jogo do xadrez. Um deles é a batalha dos números, em que um número vence o outro. O outro é o combate dos vícios e das virtudes, em jeito de batalha, sobre um tabuleiro (More, 1516/1973, p. 72).

Ao jogo, pois, é atribuido, de um lado, um valor intelectual - a "batalha dos números" se entende como desafio à inteligência, exercício de desenvolvimento da capacidade de pensamento e resolução de problemas. Por outro lado, o "combate dos vícios e das virtudes" indica a dimensão moral da atividade lúdica. Estaríamos, ao mesmo tempo, muito perto da idéia dos videogames, que em nosso tempo tonteiam as crianças e adolescentes, porém, deles inteiramente separados, enquanto a diferença tecnológica acentua a marca da amoralidade ou, seja, uma espécie própria de antivaloração.

Este jogo mostra com clareza a discórdia e a anarquia que reina entre os vícios e o seu perfeito acordo e unidade quando se opõem às virtudes. Mostra ainda os vícios que se opõem a cada uma das virtudes, como as atacam, astuciosamente e por processos indiretos, e a dureza e violência com que as enfrentam em campo aberto. Evidencia este jogo como a virtude resiste ao vício e o domina, como frustra os seus intentos e finalmente como um dos dois partidos alcança a vitória (More, 1516/1973, p. 72).

O jogo na ilha de Utopia, segundo o relato de Rafael Hitlodeu - quer dizer, de acordo com o projeto social para a Inglaterra do século XVI, crítico e irônico, desenvolvido pelo humanista Thomas More e seu amigo Erasmo de Rotterdam -, terá consciência de possuir forte caráter educativo, do intelecto e do senso moral.

Mas aqui, com perigo de vos enganardes, deveis reparar atentamente numa coisa. Pensareis talvez que são insuficientes para produzir o necessário as seis horas que ocupam no trabalho, e que são freqüentes as carências de bens úteis. Mas assim não acontece. 
Este curto tempo de trabalho é mais do que suficiente para produzir abundância, é mesmo o excedente de todas as coisas necessárias à subsistência e ao bem-estar (More, 1516/1973, p. 72).

Mais uma vez fica dito que, se houver boa distribuição do trabalho entre todos os cidadãos, as carências gerais serão atendidas e sobrará a todos tempo para o descanso e o lazer educativo, seja para o estudo ou para o jogo. Pois nos outros países há um grande número de ociosos - e, entre eles, um tanto sem distinções, contam-se as mulheres, os padres e religiosos, somados aos proprietários, ou seja, aos então ditos nobres e fidalgos, com seus criados, e também aos "mendigos válidos".

"Descobrireis, em suma, que o número dos que trabalham para prover aos bens necessários à vida do gênero humano é bem menor do que pensáveis" (More, 1516/1973, p. 73). Essa é uma das teses de moralidade estrita, digamos, de inspiração estóica, que parecem infiltrar-se nas brechas do discurso da Utopia de More. O conceito do que seja "necessário" à vida do homem é monástico. Muitas das carências atendidas pelo trabalho nas sociedades existentes são consideradas fictícias e, na verdade, desnecessárias.

Mas aqueles que trabalham, no mundo conhecido, também se situam sob a lente crítica. Nem todos os trabalhos aparecem como necessários, úteis, com sentido, pois que "prazeres desonestos" multiplicam as atividades fúteis.

Considerai, agora, como dos poucos que trabalham menos ainda se ocupam em tarefas necessárias e úteis. Já que o dinheiro é o senhor absoluto. Uma imensa quantidade de ocupações frívolas e supérfluas se multiplicam destinando-se apenas a manter o fluxo e os prazeres desonestos (More, 1516/1973, p. 73).

Além dessa distinção entre a atividade ou o labor útil e o inútil, que por enquanto guardamos sem mais detalhamento, More apresenta um verdadeiro cálculo de economia sobre o aproveitamento da força produtiva, trabalho vivo e valor do trabalho quando descarta a hipótese, infelizmente ainda sempre de novo utilizada, de resolver o problema da satisfação das carências da população apenas pelo desenvolvimento da produtividade dos que trabalham:

Se o mesmo número de trabalhadores que hoje executam a produção de tais bens fosse distribuído pelas reduzidas profissões úteis, de modo a produzir com abundância o que o consumo exige, desceriam, sem dúvida alguma, de tal modo os preços que os operários não poderiam viver do seu trabalho (More, 1516/1973, p. 73).

Antecipam-se situações futuras e a suposição de More soa a análise de mercado feita alguns séculos mais tarde. Mas, segundo ele, a solução só pode ser encontrada sobre a base da distribuição eqüitativa do labor, que é o outro lado da distribuição dos bens necessários:

Mas se todos os que se ocupam agora nessas ocupações frívolas e improdutivas, acrescidos dos que nada fazem, além de consumirem e desperdiçarem o que daria para sustentar dois operários laboriosos, se todos estes, repito, se ocupassem em profissões necessárias compreenderíeis então como seria breve o tempo útil para satisfazer as necessidades e produzir as reservas das coisas essenciais à vida, ao conforto e ao prazer, bem entendido, ao prazer natural e verdadeiro (More, 1516/1973, p. 74).

Na ilha de Utopia, que nos é dada a conhecer através do relato de Hitlodeu, garantenos More que este problema - o da distribuição do trabalho para boa distribuição dos bens já não existe. No máximo quinhentos indivíduos, entre homens e mulheres, ali foram dispensados do trabalho corporal, e entre eles se situam os magistrados que, no entanto, 
embora isentos pela lei, não se permitem gozar desse privilégio, para dar bom exemplo aos seus concidadãos.

É verdade que ainda há os que estão por lei isentos do trabalho corporal, como é o caso dos intelectuais, porém, sob essa sua dispensa do labor e o respeito de sua vocação ao estudo, permanece uma "intenção de trabalho", ou seja, se não corresponderem às expectativas de seus concidadãos, aquele privilégio lhes é retirado. Assim como também fica facultada a mobilidade contrária, pois o operário que demonstra dedicação ao estudo pode passar do labor corporal à atividade intelectual:

Se, pelo contrário, o que acontece com freqüência, um operário emprega o seu tempo livre no estudo e dele aproveita, com diligência e seriedade, isentam-se do trabalho manual e elevam-no à classe dos letrados (More, 1516/1973, p. 74).

É como se nessa observação sobre a possibilidade de substituir-se o trabalhador manual ao intelectual, e o intelectual ao manual, estivesse posta toda a peculiaridade desta concepção das diferenças dos papéis sociais, em transição de uma sociedade de estamentos, como a medieval, para uma sociedade de classes, por assim dizer, "abertas", onde a mobilidade social pode acontecer com menor rigidez, tal como seria ou, pelo menos, gostaria de ser a sociedade democrática moderna que se desenvolveria nos séculos a seguir.

Uma das características comuns a todas as utopias - e, nesse sentido, é exemplar aquela que inaugurou o termo e abriu a série variada das utopias modernas - é a de não esquecer o detalhe. A habitação e o vestuário dos utopianos são objeto de observações significativas sobre o modo virtuoso de viver, a contenção e os verdadeiros valores, que justificam evitar-se o supérfluo. Os seus usos quanto à habitação servem de lições aos contemporâneos de More, sendo que a sabedoria no uso das suas moradas é apenas um dos sinais da perfeita organização da ilha de Utopia. "Na Utopia (...) tudo está tão bem organizado e a comunidade tão bem governada que raramente acontece que tenham de voltar a escolher outro local para uma nova construção" (More, 1516/1973, p. 74).

Muitos gastos supérfluos, fúteis, são evitados, porque as habitações são usadas com sabedoria e bem conservadas, antes que substituídas:

Encontram remédio rápido e fácil para as deteriorações presentes, prevendo mesmo as possíveis. Deste modo, conservam os edifícios com pouco trabalho e pequena despesa, dando-lhes grande duração; de tal modo que os operários especializados neste trabalho quase não têm que fazer, ocupando-se em aparelhar a madeira e a pedra, para que, quando for necessário fazer alguma construção, a obra se faça rapidamente (More, 1516/1973, p. 75).

Sutil, insinua-se o desejo de liberação do trabalho. Longe da moral do trabalho, ainda debitário do espírito monástico, não só a propriedade privada e os luxos são negados, mas o trabalho também precisa ser reduzido ao mínimo. Como comenta Ernst Bloch, a existência na ilha de Utopia é humana, sobretudo, porque seus habitantes em grande parte escapam do jugo do trabalho (Bloch, 1959/1982, p. 93).

Vereis agora como são necessários poucos braços para a confecção do vestuário. Em primeiro lugar, nas horas de trabalho, cobrem-se confortavelmente com couro ou peles, vestimenta que lhes chega a durar sete anos (More, 1516/1973, p. 75).

Dito de outro modo, More insiste na origem social, ou mesmo, moral, da exploração econômica: é por causa de hábitos pouco modestos, pela futilidade e pelo excesso, que se torna necessário o trabalho. Se todos se restringissem, como na ilha de Utopia, ao eficiente e confortável, mas sem luxo ou ostentação, muito trabalho se tornaria desnecessário. "Quando 
saem, cobrem-se com um casaco que lhes tapa o grosseiro vestuário de trabalho" (More, 1516/1973, p. 75).

A simples finalidade material e básica, de proteção do frio, toma precedência sobre a aparência e o efeito simbólico social e político da veste, que pode revelar hierarquia social, prestígio, poder. Essa aparência seria também causa do trabalho excessivo e desnecessário, que a boa organização econômica deveria saber prevenir e evitar.

Estes casacos são da mesma cor, a cor natural da lã, para toda a ilha, gastando por isso muito menos tecido de lã do que as outras nações, ficando-lhes, além disso, esses tecidos muito mais baratos (More, 1516/1973, p. 75).

A uniformidade da cor serve àquela finalidade igualitária, de não permitir que se afirmem, pelo modo do vestuário, diferenças sociais de poder e honra. Nessa preocupação com evitar o excesso de trabalho pela uniformidade das vestes, pela qual, por outro lado, afirma-se claramente a igualdade social, na Utopia de More aparece algo que pode ser visto como uma antecipação dos macacões uniformes do período de Mao Tse Tung na China comunista do século XX.

Como o linho exige menos trabalho, utilizam-no com muita freqüência. Nos tecidos de linho preocupam-se apenas com a brancura, e nos de lã com a sua limpeza, sem se interessarem pela delicadeza ou finura do tecido (More, 1516/1973, p. 75).

Numa sociedade que teme o desemprego e se encontra ameaçada de diminuição e mudança radical da demanda de força de trabalho pelo avanço tecnológico e, justamente, pela má distribuição da renda e do trabalho, pode parecer estranha e deslocada a preocupação com diminuir o trabalho geral necessário. Os planejadores a serviço das administrações contemporâneas aplicam-se com afinco em "criar trabalho".

Do mesmo modo, as iniciativas privadas querem ser "criativas" na invenção de atividades produtivas, ainda que seja "criando" novas necessidades pela propaganda que, por sua vez, serão atendidas por novos produtos ou serviços que se afirmam como úteis, de modo a fazer frente às expectativas de emprego e aos problemas do desemprego provocado pela automação. Porém, no início da era moderna, esta preocupação, com possibilitar uma diminuição do trabalho social em seu todo, era perfeitamente justificada e real, e constituiu mesmo uma das mais importantes alavancas para todo o esforço de desenvolvimento tecnológico que aconteceria nos séculos a seguir; não deve ser esquecida, pois, vistas de outro modo, as chances de diminuição do trabalho trazidas pela automação podem ser consideradas positivamente, como facultadoras de menos trabalho para cada trabalhador. A idéia, a sugestão e a proposta de redução da jornada comum de trabalho continuam atuais, pelo menos ao fundo de projeção das descrições mais imediatistas.

A contenção do luxo e a limitação do consumo, em relação ao exemplo do vestuário, inspiram o comentário de More sobre a quantidade de trabalho geral que pode e deve ser reduzida. Só o excesso de alguns e o abuso tornam necessários o esforço e o sacrifício de muitos.

Eis a razão por que noutros países cada pessoa precisa de mais de quatro ou cinco trajes de cores diversas e outros tantos fatos de seda, e os elegantes de mais de uma dezena; aqui, um só fato dura-lhes, normalmente, dois anos. Que mais se há de desejar? Não se andaria mais bem vestido, nem mais confortavelmente protegido do frio, se mais fatos se tivessem (More, 1516/1973, p. 75).

Uma sutil ironia parece infiltrar-se nos interstícios do tecido desses comentários sobre o que não seria tão essencial para uma organização ideal mas, com certeza, o autor teria 
em mente a Inglaterra de Henrique VIII e a pomposidade dos trajes da corte inglesa, ao propor-lhe tal mudança de hábitos - literalmente, e por contraste, ao parecer descrever a austera sociedade da ilha de Utopia.

É assim que, ocupando-se todos em ofícios úteis, e dado que poucos trabalhadores bastam para executar determinada atividade, reinando a abundância, grande número de habitantes são mandados reparar as estradas necessitadas de conserto (More, 1516/1973, p. 75)

O conserto das estradas, como se pode ver, é pensado como o recurso aparentemente óbvio da administração que, por outro lado, dispensa grande parte do trabalho produtivo propriamente dito; isso tal como ainda o veríamos ser assim considerado em tempos avançados da modernidade, ainda há pouco, na segunda metade do século XX, e como ainda muitas vezes é lembrado hoje, neste começo de século XXI e novo milênio.

Outras vezes, quando não há necessidade desta atividade, é proclamado um decreto que determina que se ocupem menos horas de trabalho. Os magistrados não pretendem fatigar os cidadãos, ocupando-os em tarefas desnecessárias (More, 1516/1973, p. 75).

A redução da jornada de trabalho seria na Utopia determinada pela lei, instituida, literalmente, "por decreto", já que, lá como aqui, então como hoje, não parece ser fácil que as relações espontâneas entre os cidadãos encaminhem para essa boa distribuição do esforço e do lazer, conseqüentemente, do poder, onde não se estabeleçam classes em desigualdade. Os magistrados, que aplicam a lei, mantêm em vista a possibilidade de liberar os cidadãos de tarefas excessivas desnecessárias, pois o trabalho não contém em si aquela mágica propriedade, moral ou existencial, que a modernidade, mais tarde, parece ter imprimido nas almas dos trabalhadores e administradores.

O objetivo das instituições sociais é unicamente que o tempo que se poupe, além das ocupações e mesteres necessários à comunidade, seja aproveitado por todos os cidadãos para se libertarem da escravidão do corpo, cultivando livremente o espírito. Nisto consiste, para os utopianos, a felicidade da vida (More, 1516/1973, p. 75).

Nesse sentido, estamos em nossos dias bem distanciados da Utopia idealizada por More, como também da escala de valores embutida no desejo de liberar os cidadãos - todos eles - para a "cultura livre do espírito". Pois mesmo os bem situados na sociedade pósindustrial e de consumo muitas vezes preferem usar o tempo livre na atividade física ou na cultura do corpo (o que evidentemente também é bom e saudável) e isso talvez exatamente porque a maioria das formas do trabalho se distanciou do esforço físico.

Neste tempo em que esteve no centro da preocupação social e política e, de certo modo, na base da construção cultural, mesmo religiosa, o mundo do trabalho humano perdeu a oportunidade de realizar a síntese - não apenas entre labor e descanso, bem como entre esforço físico e intelectual - entre o movimento do corpo e a respiração do espírito. Novas sínteses deverão ser buscadas, muito embora à margem do mundo do trabalho.

Durante estes quinhentos anos que nos separam da utopia de More, para o bem e para o mal, consciente ou intuitivamente e mesmo inconscientemente, as atividades produtivas ocuparam um lugar privilegiado no todo da vida das sociedades modernas e contemporâneas.

Mesmo a ciência social, sobretudo a sociologia, de um modo ou outro, construiu-se sobre o fundamento produtivo destas sociedades industriais, procurando entendê-lo, criticálo, prevê-lo, transformá-lo. 
Neste momento, parece evidente que atravessamos uma nova passagem. Entramos talvez num novo período da história da humanidade em que, pelos avanços tecnológicos que acompanharam o período e pela própria inércia da conquista industrial, embora a utilizando, nela não encontramos mais a principal ocupação para a maioria dos habitantes do planeta.

Em que a Utopia de Thomas More pode sugerir ainda algo importante para a reforma e reelaboração do trabalho neste mundo em transição? É o que a meditação sobre estas páginas, espero, levará a encontrar.

Work and utopia in the modern times

The text explores the book Utopia (1516), of Thomas More, specially what is said there about work, its organization and its distribution in the society. It begins by pointing out the controversy around the book, which is included in the tradition of writing in ductus obliquus, as said by Leo Strauss and Miguel Abensour, and proceeds to a review of what More says about work, when he writes about that imaginary and ideal island.

Keywords: Utopia, More, ductus obliquus, work, agriculture, handwork, moderation, equality.

Endereço para contato com a autora: suzanaalb@viavale.com.br

Manuscrito recebido em: 17/06/2003

Envio de pareceres à autora em: 04/08/2003

Aprovado para publicação em: 27/08/2003

\section{Referências bibliográficas}

Abensour, M. (2000). L'utopie de Thomas More à Walter Benjamin. Paris: Sens \& Tonka.

Bloch, E. (1974). La philosophie de la rénaissance. Paris: Payot.

Bloch, E. (1982). Le Principe Esperance, II (1 ${ }^{\underline{a}}$ ed. alemã). Paris: Gallimard. (Originalmente publicado em 1959)

Campanella, T. (1980). A cidade do sol. Lisboa: Guimarães.

Chambers, R. W. (1935). Thomas More. Londres: Jonathan Cape.

Kautsky, K. (1920). Vorläufer des neuen sozialismus. Stuttgart (Originalmente publicado em 1913)

More, T. Utopia. Lisboa: Europa-América, 1973. (Originalmente publicado em 1516)

Strauss, L. (1979). Um art d'écrire oublié. Poétique, 98, 244. 